\title{
Chemical Preservatives-Based Storage Studies and Ethanol Production from Juice of Sweet Sorghum Cultivar, ICSV 93046
}

\author{
C. Ganesh Kumar • P. Srinivasa Rao • \\ Soma Gupta $\cdot$ Jayalakshmi Malapaka • \\ Ahmed Kamal
}

Received: 19 May 2014 / Accepted: 20 August 2014

(C) Society for Sugar Research \& Promotion 2014

\begin{abstract}
Sweet sorghum is an ideal feedstock for ethanol production, in view of the increased global demand for biofuels. Sweet sorghum juice is a perishable commodity and the stalk juice has a short shelf life $(4-5 \mathrm{~h})$ postcrushing due to its high fermentable sugar content and the rapid sugar degradation during storage is due to the metabolic activities of contaminating spoilage bacteria. Hence, the preservation of the juice is required for quality retention and to extend the storage shelf life of the juice. In the present study, the effect of chemical preservatives to extend the storage stability of sweet sorghum juice and its later bioconversion to ethanol was studied. Among the chemical preservatives evaluated, the juice samples spiked with sodium benzoate and sorbic acid delayed the increase in reducing sugars and thus prevented browning of juice during storage. Sodium benzoate and sorbic acid-spiked samples showed a decrease in the total sugar content from 13.03 to $10.7 \%$ and 11.35 to $10.16 \%$, respectively, over a storage period of $96 \mathrm{~h}$. Ethanol yield was in the range of $0.425-0.475 \mathrm{~g} \mathrm{~g}^{-1}$ and $0.405-0.445 \mathrm{~g} \mathrm{~g}^{-1}$ with optimal efficiency of 93 and $92 \%$ for sodium benzoate and sorbic acid, respectively, while the control showed a reduction in yield from 0.36 to $0.26 \mathrm{~g} \mathrm{~g}^{-1}$ and efficiency by $57 \%$. Sodium benzoate (at $1,000 \mathrm{ppm}$ concentration) was
\end{abstract}

C. Ganesh Kumar and P. Srinivasa Rao these authors contributed equally.

C. Ganesh Kumar $(\varangle) \cdot$ S. Gupta · J. Malapaka · A. Kamal Chemical Biology Laboratory, CSIR-Indian Institute of Chemical Technology, Uppal Road, Hyderabad 500007, India e-mail: cgkumar@iict.res.in; cgkumar5@gmail.com

P. Srinivasa Rao

International Crops Research Institute for the Semi-Arid Tropics,

Patancheru, Hyderabad 502324, India identified as suitable preservative to retain the quality and extend the storage shelf life of fresh sweet sorghum juice up to 2 days at $37^{\circ} \mathrm{C}$.

Keywords Sweet sorghum juice - Sodium benzoate . Sorbic acid $\cdot$ Preservatives $\cdot$ Storage $\cdot$ Ethanol

\section{Introduction}

Sweet sorghum (Sorghum bicolor (L.) Moench) can be cultivated in tropical, sub-tropical, temperate, semi-arid regions as well as in marginal and poor quality soils due to its high carbon assimilation $\left(50 \mathrm{~g} \mathrm{~m}^{-2} \mathrm{day}^{-1}\right)$, shorter growing period, low water requirement $\left(4,000\right.$ cubic $\left.\mathrm{m} \mathrm{ha}^{-1}\right)$, wider adaptability and special ability to accumulate high quantities of fermentable sugars in the stalks (Reddy et al. 2005), that favors ethanol production (Laopaiboon et al. 2009; Wu et al. 2010). This multipurpose biofuel feedstock offers grain for human consumption, fodder for livestock and ethanol for transportation purposes over other biofuel feedstocks such as sugarcane, corn grain, cassava, sugarbeet, jatropha, etc. (Srinivasa Rao et al. 2009). Sweet sorghum is best suited for ethanol production in view of its high reducing sugar content when compared to sugarcane (Huilgol and Misale 2004); with high water use efficiency, radiation use efficiency and is widely believed to be a climate change ready feedstock (Srinivasa Rao et al. 2011). Moreover, the sweet sorghum juice-derived ethanol (Sorganol) is environment-friendly, free of sulphur and aldehydes (Kundiyana 1996).

Sweet sorghum juice contains approximately 16-18\% fermentable sugars, amenable for direct fermentation by yeast to ethanol. However, the technical challenge of sweet sorghum value chain is that the stalk juice has a short shelf life (4-5 h) post-crushing due to its high fermentable sugar 
content, and the rapid sugar degradation during storage is due to the metabolic activities of various contaminating spoilage bacteria (Srinivasa Rao et al. 2012). Thus, the preservation and storage of sweet sorghum juice is needed for its further utilization in ethanol production, as an alternate energy source that is renewable, sustainable, efficient, cost-effective, convenient and safe (Wyman and Goodman 1993; Chum and Overend 2001). The different preservation methods used in the food industry are the removal of water content, controlling temperature, freezing, drying, $\mathrm{pH}$ control, irradiation, vacuum packaging, modified atmosphere packaging, aseptic packaging, acidification, fermentation, heating (pasteurization and sterilization) and addition of chemical preservatives (Gould 1989, 2000). The existing propensities for juice preservation depends on the utilization of these methods that assures quality products with no added preservatives, high nutritional value, as well as safe from a microbiological perspective at the yeast fermentation step which is critical for the viability of the whole value chain (Srinivasa Rao et al. 2012).

In food industry, the most common preservatives used include benzoic acid, sodium benzoate, sorbic acid and potassium sorbate. In view of their established antimicrobial activity, these preservatives are frequently used in fruit pulps and juices for extending their storage shelf life (Sofos and Busta 1981; Manganelli and Casolari 1983; Lück 1990). In USA and Europe, sodium benzoate has Generally Recognized as Safe (GRAS) status for use in foods (Hussain et al. 2011). Sorbic acid and potassium sorbate are effective preservatives against a wide spectrum of food spoilage microorganisms acting at low $\mathrm{pH}$ that persist to be efficient at $\mathrm{pH}$ 6.5. Sorbic acid is tasteless, odorless and non-toxic preservative and finds use in a wide range of food products including cheese, yogurt, sour cream, margarine, mayonnaise, bread, cakes, beverages, fermented vegetables, fruit products, smoked and salted fish (Hussain et al. 2010). In the present study, the effect of six chemical preservatives, namely, benzoic acid, sodium benzoate, sorbic acid, citric acid, sodium citrate and ascorbic acid, were evaluated on the stability of sweet sorghum juice to enhance its storage shelf life and also their effect on ethanol fermentation by yeast.

\section{Materials and Methods}

\section{Crop Cultivation and Management}

The sweet sorghum cultivar, ICSV 93046, was cultivated during the post-rainy (rabi) season (October-February), 2010-2011 in vertisols of the experimental farm of the International Crops Research Institute for the Semi-Arid Tropics (ICRISAT), located in Patancheru, Andhra Pradesh,
India (altitude $545 \mathrm{~m}$ above mean sea level, latitude $17.53^{\circ} \mathrm{N}$ and longitude $78.27^{\circ} \mathrm{E}$ ). This cultivar was sown in a plot size of $3 \mathrm{~m}$ wide and $4 \mathrm{~m}$ long, i.e. four rows of four meters long spaced at $75 \mathrm{~cm} \times 15-20 \mathrm{~cm}$. The planting was done on ridges with a plant stand of about $100,000 \mathrm{ha}^{-1}$. Sweet sorghum was initially planted dense but 15 days later after seedling emergence (DAS) thinned to one plant in each hill. Hand weeding was done followed by two inter-cultivations. Surface irrigation was applied in furrows to the crop to maintain proper growth. Standard agronomic package of practices (80-40-0 NPK ha ${ }^{-1} ; 2 / 3$ rd $\mathrm{N}$ and total $\mathrm{P}$ as basal dose and 1/3rd at 25 DAS) and plant protection measures were adopted throughout the crop growth period in all the plots. After flowering, sorghum heads were covered with nylon bags for protection against bird damage on the developing grain. All the four rows were harvested at physiological maturity (when hilum turns black). The stalks were squeezed once for juice extraction on a three-roller cane press mill. The juice was sieved through a muslin cloth to remove the plant parts that come while extracting the juice. The juice was collected into sterile sample bottles and then transported under cold ice-jacketed conditions to the laboratory for further analysis. Data on juice yield ( $\left.\mathrm{t} \mathrm{ha}^{-1}\right), \mathrm{pH}$ and the stalk yield ( $\left.\mathrm{t} \mathrm{ha}^{-1}\right)$ were collected following standard procedures for each plot. Approximate sugar yield ( $\left.\mathrm{t} \mathrm{ha}^{-1}\right)$ was estimated as the product of Brix\% and juice yield ( $\mathrm{t} \mathrm{ha}^{-1}$ ) (Wortmann et al. 2010).

\section{Effect of Different Preservatives}

Different chemical preservatives used in the study were benzoic acid, sodium benzoate, sorbic acid, citric acid, sodium citrate and ascorbic acid. All these chemicals used were of analytical grade and procured from Sisco Research Laboratories (SRL), Mumbai, India. These chemical preservatives were initially spiked at a concentration of $1,000 \mathrm{ppm}$ to $100 \mathrm{ml}$ of each juice sample. Controls were run in parallel without addition of any preservative to the juice sample. These juice samples were stored at $37^{\circ} \mathrm{C}$ for 4 days. Experiments were carried out in triplicates and sample aliquots were collected at $24 \mathrm{~h}$ periodic intervals for the analysis of different sugars (glucose, fructose and sucrose) and ethanol yield.

Inoculum Preparation

Saccharomyces cerevisiae strain ICTY 417 previously isolated and maintained in the in-house culture collection of CSIR-Indian Institute of Chemical Technology (IICT), Hyderabad, India, identified as promising ethanol producer, was cultured in yeast extract-malt extract (YM) broth at $30{ }^{\circ} \mathrm{C}$ and agitated on a gyratory shaker at $150 \mathrm{rev} \mathrm{min}^{-1}$ for $18 \mathrm{~h}$. The actively growing cells in the broth with an 
absorbance of about 0.5 at $600 \mathrm{~nm}$ which corresponded to $10^{6} \mathrm{CFU} \mathrm{ml}{ }^{-1}$ served as inoculum for ethanol production.

\section{Fermentation Studies}

Sweet sorghum juice $(600 \mathrm{ml})$ was dispensed in two 1,000 $\mathrm{ml}$ Erlenmeyer flasks and sodium benzoate and sorbic acid as preservatives were added individually at a concentration of 1,000 ppm per $100 \mathrm{ml}$ sample and a third 1,000 ml Erlenmeyer flask containing $600 \mathrm{ml}$ of juice sample with no preservatives served as control. All these three flasks were incubated at room temperature $\left(37^{\circ} \mathrm{C}\right)$. At zero hour period, $100 \mathrm{ml}$ aliquots of the juice with and without preservatives was sampled from each of these flasks to which mineral salts $\left(0.05 \% \mathrm{MgSO}_{4}\right.$ and $\left.0.2 \%\left(\mathrm{NH}_{4}\right)_{2} \mathrm{SO}_{4}\right)$ were added and autoclaved at $121{ }^{\circ} \mathrm{C}$ for $20 \mathrm{~min}$. These flasks were cooled, inoculated with $1 \mathrm{ml}$ of yeast culture (inoculum $\mathrm{OD}_{600} 0.5$ ) and incubated at $30{ }^{\circ} \mathrm{C}$ with agitation at $150 \mathrm{rpm}$. Further, at $24 \mathrm{~h}$ periodic intervals, $100 \mathrm{ml}$ of the juice sample aliquots (control and with preservatives) was collected from the flasks incubated at room temperature and processed as described above. This sampling process was continued till $96 \mathrm{~h}$. The fermented samples $(10 \mathrm{ml})$ were withdrawn from the inoculated flasks at every $24 \mathrm{~h}$ interval for 2 days, centrifuged at $8,000 \mathrm{rpm}$ for 10 min for cell separation and the cell-free supernatants were analyzed on gas chromatography (GC) to quantify the amount of ethanol produced. The reducing sugar content in the juice samples before and after fermentation was also analyzed by dinitrosalicylic acid (DNS) method (Miller 1959).

\section{Analytical Methods}

Sugar concentration in terms of Brix (\%) was measured using a hand-held pocket refractometer (Model PAL, Atago Co. Ltd., Tokyo, Japan) (Kumar et al. 2010). The pH was recorded using a microprocessor-based $\mathrm{pH}$ meter (Model DPH506, Global Electronics, Hyderabad, India). Between two different sample readings, the refractometer and the $\mathrm{pH}$ meter were cleaned with distilled water and dried with a paper towel. The sweet sorghum juice was centrifuged at $10,000 \mathrm{rpm}$ for $10 \mathrm{~min}$ and total soluble sugars (TSS) content in the supernatant was determined using phenol sulphuric acid method (Dubois et al. 1956), while the reducing sugar content was determined using 3,5-dinitrosalicylic acid (DNS) method (Miller 1959). Sugar profiling to determine the contents of individual hexose sugars, i.e., glucose, fructose and sucrose, present in the supernatant were analyzed on a HPLC system (Shimadzu, Kyoto, Japan) equipped with a Luna $5 \mu \mathrm{m} \mathrm{NH} 2100 \mathrm{R}$ column $(4.6 \times 250 \mathrm{~mm}, 5 \mu \mathrm{m}$ particle size, Phenomenex, Inc., USA) (Kumar et al. 2010).

In addition, the ethanol concentrations $\left(\mathrm{P}, \mathrm{g} \mathrm{L}^{-1}\right)$ in the samples were analyzed using the gas chromatograph
(Model GC2014, Shimadzu, Kyoto, Japan) equipped with a flame ionization detector and interfaced with a Zebron ZB624 column (Phenomenex Inc., USA) having dimensions of $30 \mathrm{~m} \times 0.53 \mathrm{~mm} \times 3.00 \mu \mathrm{m}$, and set at $60{ }^{\circ} \mathrm{C}$. Ethanol (GR grade) was used for the construction of standard curve, while isopropanol (GR grade) was used as an internal standard. GC operation conditions: Oven temperature $60{ }^{\circ} \mathrm{C}$; injecting temperature $250{ }^{\circ} \mathrm{C}$ using nitrogen as carrier gas and hydrogen as a flaming gas both at a flow rate of $41 \mathrm{~mL} / \mathrm{min}$ with a column flow rate of $1.9 \mathrm{~mL} / \mathrm{min}$; flame ionization detector temperature was $280{ }^{\circ} \mathrm{C}$; helium gas was used for cooling the column. Head pressure was $11.5 \mathrm{kPa}$ with a $25: 1$ split ratio; sample volume used was 1 $\mu \mathrm{L}$. All experiments were carried out in triplicates and the data values are represented as mean \pm standard error (SE) and the SE values are shown as $Y$-error bars in all figures.

Kinetic studies were also carried out for the fermented samples. The ethanol concentration estimations were performed at periodic intervals of $4 \mathrm{~h}$ up to $60 \mathrm{~h}$. The ethanol yield $\left(\mathrm{Y}_{\mathrm{p} / \mathrm{s}}\right)$ was calculated as the actual ethanol produced and expressed as $\mathrm{g}$ ethanol per $\mathrm{g}$ total sugar utilized $\left(\mathrm{g} \mathrm{g}^{-1}\right)$. The ethanol productivity $\left(\mathrm{Q}_{\mathrm{p}}, \mathrm{g} \mathrm{L}^{-1} \mathrm{~h}^{-1}\right)$ and the percentage of conversion efficiency or yield efficiency $\left(E_{\mathrm{y}}\right)$ were calculated using the following equations (Laopaiboon et al. 2007):

$\mathrm{Q}_{\mathrm{P}}=\mathrm{P} / \mathrm{t}$ and $\mathrm{E}_{Y}=\left(\mathrm{Y}_{\mathrm{p} / \mathrm{s}} \times 100\right) / 0.51$,

where $\mathrm{P}$ is the actual ethanol concentration produced $\left(\mathrm{g} \mathrm{L}^{-1}\right), \mathrm{t}$ is the fermentation time (h) giving the highest ethanol concentration and 0.51 is the maximum theoretical ethanol yield of glucose consumption.

\section{Results and Discussion}

Sugar Analysis as a Function of Fermentation Time in Presence of Different Chemical Preservatives

Storage studies were carried out on fresh sweet sorghum juice samples spiked with different chemical preservatives like benzoic acid, sodium benzoate, sorbic acid, citric acid, sodium citrate and ascorbic acid. The results clearly indicated that the amount of total soluble sugars and the percentage of the individual hexose sugars like glucose, fructose and sucrose as a function of time decreased significantly in the juice samples spiked with citric acid (Fig. 1a), sodium citrate (Fig. 1b), ascorbic acid (Fig. 1c) and benzoic acid (Fig. 1d), indicating the deterioration of sugars as compared to the juice samples-spiked with sodium benzoate (Fig. 1e) and sorbic acid (Fig. 1f). It was also observed that the amount of reducing sugars increased, while the amount of non-reducing sugars decreased with an increase in the storage time as a result of breakdown of non- 
reducing sugar (sucrose) to reducing sugars. The fructose and glucose content increased from 1.69 to $4.42 \%$ and 3.07 to $5.41 \%$, respectively, while sucrose content decreased from 8.27 to $0.87 \%$ in sodium benzoate-spiked samples as depicted in Fig. 1e. The sorbic acid-spiked samples showed an increase in fructose and glucose content from 1.47 to $3.3 \%$ and 2.7 to $5.84 \%$, respectively, whereas sucrose content decreased from 7.18 to $1.02 \%$ as evident from Fig. 1f. The total soluble sugar content decreased from 13.03 to $10.7 \%$ and 11.35 to $10.16 \%$ for sodium benzoate and sorbic acid-spiked samples, respectively. The data corroborates with an earlier study where the juice samples stored at room temperature $\left(\sim 25^{\circ} \mathrm{C}\right)$, resulted in sharp decrease in sucrose content ( $31 \%$ ) out of the total soluble sugar content after 5th day (Wu et al. 2010). The addition of sodium benzoate or sorbic acid at $1,000 \mathrm{ppm}$ seemed to be more effective in quality retention and increase in the storage shelf life of sorghum juice from $5 \mathrm{~h}$ to 2 days at $37^{\circ} \mathrm{C}$. The deterioration of fresh sorghum juice (control) was observed with an obvious browning and rapid increase of viscosity (visual observation) which may be due to the fermentation by spoilage microflora within $12 \mathrm{~h}$ (Srinivasa Rao et al. 2012). Further, the juice deterioration was comparatively much lower in the sodium benzoate and sorbic acid-spiked juice samples suggesting their significant positive effect in restricting the microbial growth in the juice.
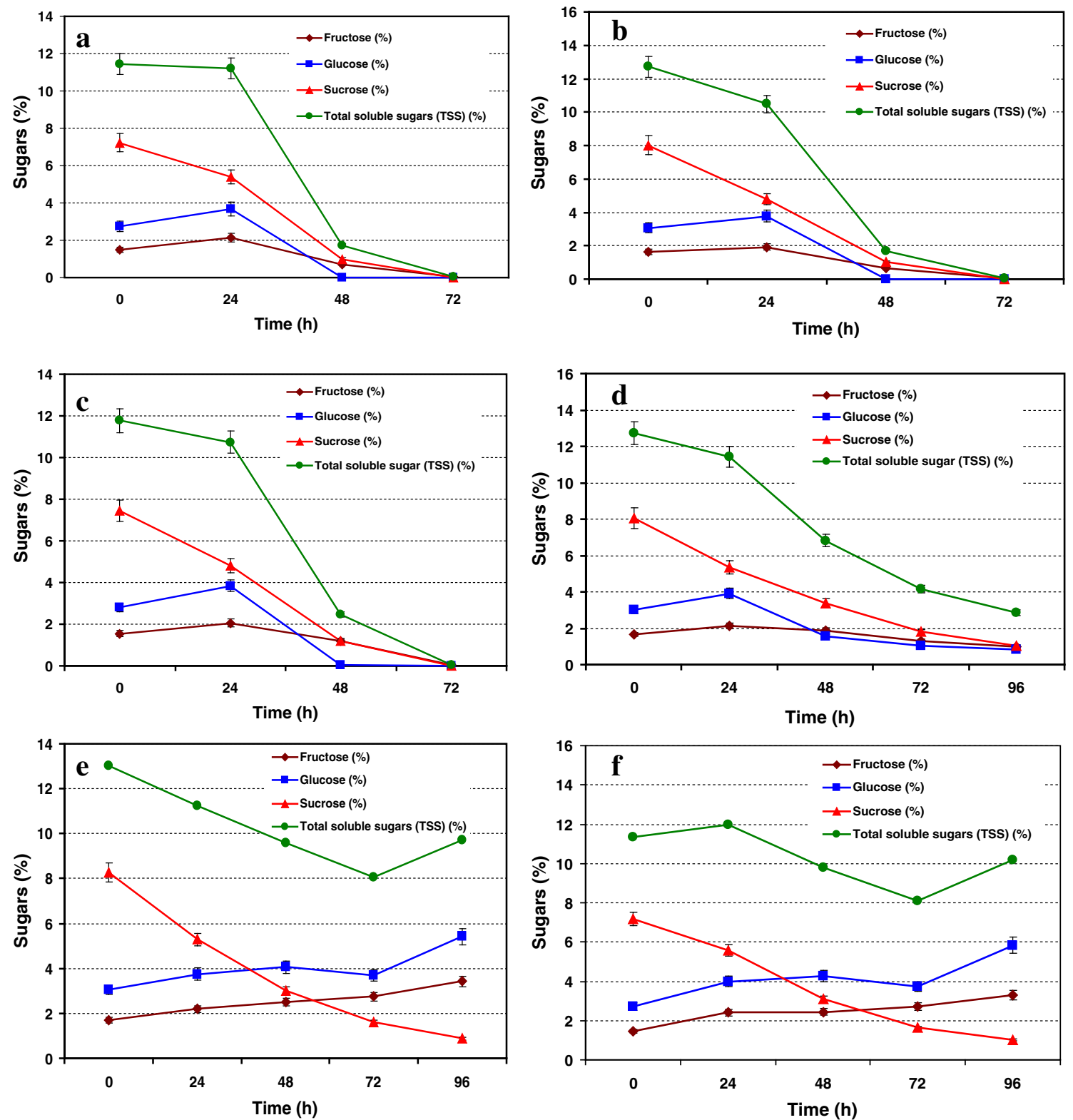

Fig. 1 Sugar analysis of sweet sorghum juice sample spiked with a citric acid, b sodium citrate, $\mathbf{c}$ ascorbic acid, $\mathbf{d}$ benzoic acid, e sodium benzoate, and $\mathbf{f}$ sorbic acid as a function of incubation period 

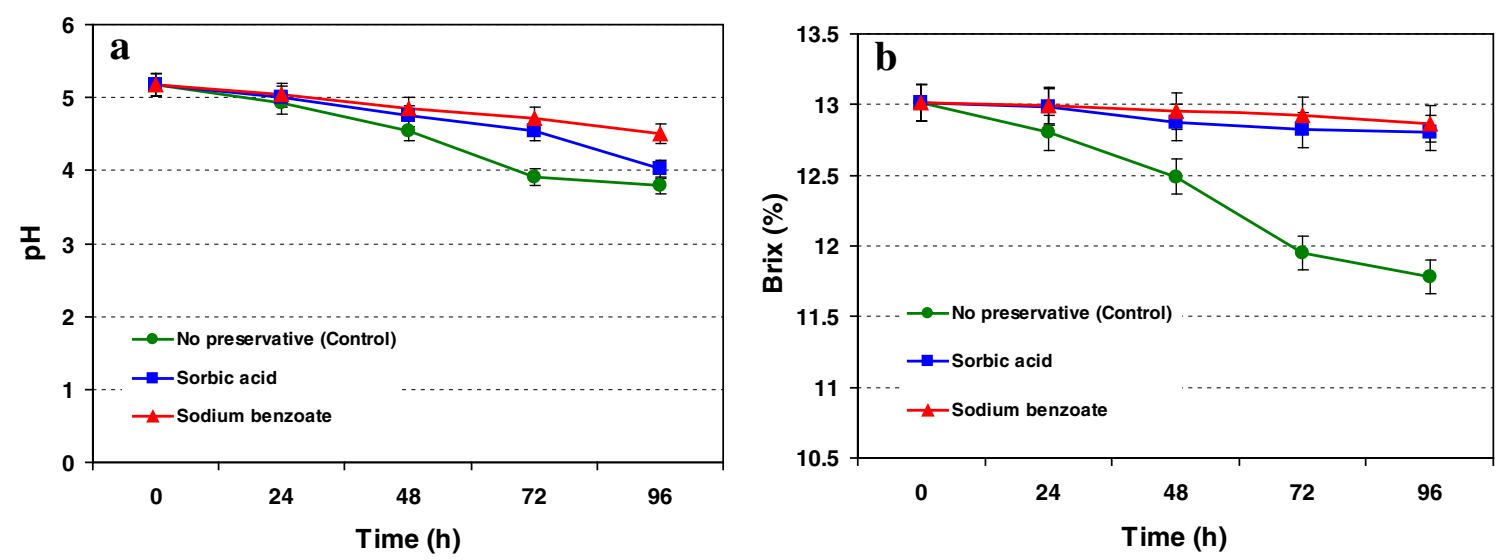

Fig. 2 Effect of different preservatives on $\mathbf{a} \mathrm{pH}$ and $\mathbf{b}$ Brix\% values of sweet sorghum juice as a function of incubation period

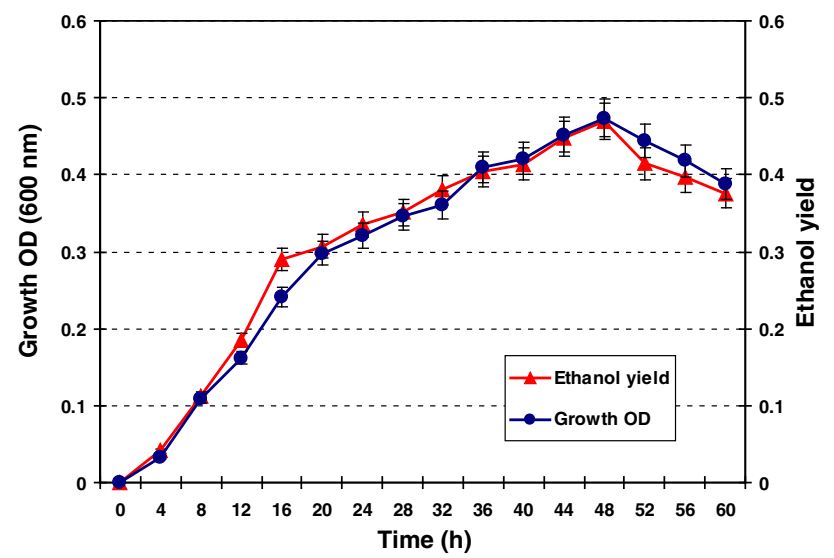

Fig. 3 Growth kinetics profile of $S$. cerevisiae strain ICTY 417 with reference to ethanol production

Considering these advantages, sodium benzoate and sorbic acid preservatives exhibited higher storage stability as compared to the other tested preservatives and these were only selected for further fermentation studies. It was earlier demonstrated that some yeast strains are resistant to these preservatives (Warth 1985), and this feature can be very well exploited in the context of yeast fermentation.

\section{pH Changes as a Function of Fermentation Time}

Based on the results shown in Fig. $2 \mathrm{a}$, the $\mathrm{pH}$ changes observed in the sorghum juice were considerable and comparable. The $\mathrm{pH}$ value decreased with an increase in the fermentation time in the control from $\mathrm{pH} 5.18$ to $\mathrm{pH} 3.8$ as compared to the preservative-spiked samples which decreased from $\mathrm{pH} 5.18$ to $\mathrm{pH} 4.5$ for sodium benzoate and $\mathrm{pH} 5.18$ to $\mathrm{pH} 4.02$ for sorbic acid. In addition, the lowering of $\mathrm{pH}$ was somewhat more in the sorbic acid-spiked sample as compared to the benzoic acid-spiked sample. It was also noticed that the $\mathrm{pH}$ changes were not that significant and remained fairly constant at $\mathrm{pH} 4$. This observation can be explained by the fact that carbon dioxide released during yeast fermentation is dissolved in the fermented juice which is converted to carbonic acid producing carbonate ions and protons, and this maintained the $\mathrm{pH}$ of the juice at a relatively constant value of $\mathrm{pH} 4$ (Shen et al. 2004). This lowering of $\mathrm{pH}$ value in the preservative-spiked samples may also contribute to the inhibition in growth of spoilage microbes and the extension in storage shelf life of the juice. The changes in $\mathrm{pH}$ value of the juice remained almost constant during the initial period of the fermentation after which it dropped and remained constant for the rest of the fermentation period. These results were comparable with some earlier fermentation studies carried out on sweet sorghum juice under different conditions (Khongsay et al. 2010; Ariyajarearnwong et al. 2011).

Brix Value Changes as a Function of Fermentation Time

A steady state changes in the Brix values were observed in the control samples as compared to the preservative-spiked samples (Fig. 2b). The Brix values reduced from an initial Brix value of 13 to $11.78 \%$ in case of control as compared to the sorbic acid and sodium benzoate-spiked juice samples which reduced to 12.8 and $12.86 \%$, respectively, after $96 \mathrm{~h}$ incubation.

\section{Ethanol Production as a Function of Fermentation Time}

The ethanol production paralleled with the yeast growth and the fermentation of juice showed maximum concentration of ethanol $\left(0.69 \mathrm{~g} \mathrm{~g}^{-1}\right)$ after $48 \mathrm{~h}$ with the onset of the stationary phase of growth, after which a decrease in the ethanol concentration was observed (Fig. 3). Since the optimal ethanol production was observed at $48 \mathrm{~h}$, the later fermentation studies were carried out only for $48 \mathrm{~h}$ incubation. 
Table 1 Kinetic parameters of batch ethanol production as a function of fermentation time by S. cerevisiae strain ICTY417 from sweet sorghum juice samples spiked with and without chemical preservatives like sorbic acid and sodium benzoate and stored for $96 \mathrm{~h}$

\begin{tabular}{|c|c|c|c|c|}
\hline \multirow[t]{2}{*}{ Juice samples } & \multicolumn{4}{|c|}{ Parameters (mean $\pm \mathrm{SE}$ ) } \\
\hline & $\mathrm{P}\left(\mathrm{g} \mathrm{L}^{-1}\right)$ & $Y_{p / s}\left(g^{-1}\right)$ & $\mathrm{Q}_{\mathrm{p}}\left(\mathrm{g} \mathrm{L}^{-1} \mathrm{~h}^{-1}\right)$ & $\mathrm{E}_{\mathrm{y}}^{\#}(\%)$ \\
\hline \multicolumn{5}{|l|}{$0 \mathrm{~h}$ storage period } \\
\hline Control (24 h fermentation) & $48.41 \pm 0.074$ & $0.40 \pm 0.440$ & $2.02 \pm 0.251$ & $77.98 \pm 0.108$ \\
\hline Control (48 h fermentation) & $50.62 \pm 0.140$ & $0.40 \pm 0.615$ & $1.05 \pm 0.591$ & $79.09 \pm 0.717$ \\
\hline \multicolumn{5}{|l|}{$24 \mathrm{~h}$ storage period } \\
\hline Control (24 h fermentation) & $51.89 \pm 0.374$ & $0.33 \pm 0.412$ & $2.16 \pm 0.576$ & $64.50 \pm 0.728$ \\
\hline Sorbic acid ( $24 \mathrm{~h}$ fermentation) & $52.23 \pm 0.209$ & $0.43 \pm 0.266$ & $2.17 \pm 0.581$ & $85.49 \pm 0.810$ \\
\hline Sodium benzoate ( $24 \mathrm{~h}$ fermentation) & $52.14 \pm 0.308$ & $0.44 \pm 0.488$ & $2.17 \pm 0.651$ & $85.68 \pm 0.923$ \\
\hline Control (48 h fermentation) & $52.97 \pm 0.091$ & $0.35 \pm 0.487$ & $1.10 \pm 0.362$ & $69.01 \pm 0.705$ \\
\hline Sorbic acid (48 h fermentation) & $53.33 \pm 0.194$ & $0.44 \pm 0.746$ & $1.11 \pm 0.680$ & $89.45 \pm 0.629$ \\
\hline Sodium benzoate ( $48 \mathrm{~h}$ fermentation) & $53.3 \pm 0.931$ & $0.44 \pm 0.407$ & $1.11 \pm 0.692$ & $90.45 \pm 0.875$ \\
\hline \multicolumn{5}{|l|}{$48 \mathrm{~h}$ storage period } \\
\hline Control (24 h fermentation) & $53.81 \pm 0.340$ & $0.31 \pm 0.404$ & $2.24 \pm 0.357$ & $60.19 \pm 0.772$ \\
\hline Sorbic acid (24 h fermentation) & $54.27 \pm 0.146$ & $0.45 \pm 0.561$ & $2.26 \pm 0.389$ & $85.03 \pm 0.795$ \\
\hline Sodium benzoate ( $24 \mathrm{~h}$ fermentation) & $55.06 \pm 0.092$ & $0.45 \pm 0.808$ & $2.29 \pm 0.491$ & $87.41 \pm 0.673$ \\
\hline Control (48 h fermentation) & $56.97 \pm 0.618$ & $0.34 \pm 0.297$ & $1.18 \pm 0.305$ & $66.47 \pm 0.037$ \\
\hline Sorbic acid (48 h fermentation) & $57.54 \pm 0.610$ & $0.44 \pm 0.471$ & $1.20 \pm 0.584$ & $92.74 \pm 0.904$ \\
\hline Sodium benzoate ( $48 \mathrm{~h}$ fermentation) & $57.96 \pm 0.161$ & $0.47 \pm 0.509$ & $1.21 \pm 0.714$ & $93.13 \pm 0.273$ \\
\hline \multicolumn{5}{|l|}{$72 \mathrm{~h}$ storage period } \\
\hline Control (24 h fermentation) & $51.44 \pm 0.971$ & $0.29 \pm 0.451$ & $2.14 \pm 0.728$ & $57.05 \pm 0.609$ \\
\hline Sorbic acid ( $24 \mathrm{~h}$ fermentation) & $51.55 \pm 0.484$ & $0.43 \pm 0.847$ & $2.15 \pm 0.892$ & $84.31 \pm 0.491$ \\
\hline Sodium benzoate ( $24 \mathrm{~h}$ fermentation) & $52.53 \pm 0.114$ & $0.44 \pm 0.230$ & $2.19 \pm 0.147$ & $86.07 \pm 0.408$ \\
\hline Control (48 h fermentation) & $52.60 \pm 0.106$ & $0.32 \pm 0.099$ & $1.09 \pm 0.579$ & $62.54 \pm 0.627$ \\
\hline Sorbic acid (48 h fermentation) & $52.85 \pm 0.470$ & $0.44 \pm 0.309$ & $1.10 \pm 0.672$ & $88.66 \pm 0.182$ \\
\hline Sodium benzoate ( $48 \mathrm{~h}$ fermentation) & $52.64 \pm 0.493$ & $0.44 \pm 0.467$ & $1.09 \pm 0.877$ & $90.47 \pm 0.220$ \\
\hline \multicolumn{5}{|l|}{$96 \mathrm{~h}$ storage period } \\
\hline Control (24 h fermentation) & $49.03 \pm 0.368$ & $0.26 \pm 0.476$ & $2.04 \pm 0.119$ & $50.98 \pm 0.375$ \\
\hline Sorbic acid (24 h fermentation) & $49.10 \pm 0.589$ & $0.41 \pm 0.374$ & $2.04 \pm 0.772$ & $80.39 \pm 0.191$ \\
\hline Sodium benzoate ( $24 \mathrm{~h}$ fermentation) & $49.08 \pm 0.491$ & $0.40 \pm 0.701$ & $2.04 \pm 0.684$ & $79.80 \pm 0.275$ \\
\hline Control (48 h fermentation) & $49.54 \pm 0.402$ & $0.29 \pm 0.905$ & $1.03 \pm 0.557$ & $57.45 \pm 0.621$ \\
\hline Sorbic acid (48 h fermentation) & $49.94 \pm 0.835$ & $0.42 \pm 0.106$ & $1.04 \pm 0.721$ & $88.76 \pm 0.040$ \\
\hline Sodium benzoate ( $48 \mathrm{~h}$ fermentation) & $49.95 \pm 0.676$ & $0.42 \pm 0.351$ & $1.04 \pm 0.117$ & $90.96 \pm 0.237$ \\
\hline
\end{tabular}

$P$ actual ethanol concentration produced, $Y_{p / s}$ ethanol yield, $Q_{p}$ ethanol productivity, $E_{\mathrm{y}}^{\#}$ percentage of conversion efficiency or yield efficiency

The total soluble sugars and total soluble solids present at the beginning of the fermentation were $150 \mathrm{~g} \mathrm{~L}^{-1}$ and $13^{\circ} \mathrm{Brix}$, respectively. The fermentation was carried out for sodium benzoate and sorbic acid-spiked juice samples and in juice sample without preservative, as a control. Ethanol yield $\left(\mathrm{g} \mathrm{g}^{-1}\right)$ as a function of fermentation time was estimated for control and sodium benzoate-spiked samples (Fig. 1e) and for control and sorbic acid-spiked samples (Fig. 1f) at different time durations like 0, 24, 48, 72 and $96 \mathrm{~h}$. It was observed that ethanol yield was highest after $48 \mathrm{~h}$ of fermentation in case of both sodium benzoate and sorbic acid-spiked samples. After $48 \mathrm{~h}$, the ethanol production decreased which might be due to the ethanol feedback inhibition. A similar trend was observed in case of blank (un-spiked sample). Furthermore, the production followed a somewhat constant trend in both the preservative-spiked samples, while in case of control, the ethanol production was found to be lower as compared with the preservative-spiked samples. The decrease in the ethanol production of the control samples were the result of the rapid deterioration of the fermentable juice components by microorganisms.

Based on the kinetic parameters of batch ethanol production as a function of fermentation time (Table 1), it can be inferred that at $24 \mathrm{~h}$ of juice preservation, the sorbic acid-spiked sample recorded $21 \%$ higher fermentation 
efficiency at $24 \mathrm{~h}$ of fermentation period, while sodium benzoate-spiked sample exhibited $21.2 \%$ increased fermentation efficiency over the control. However, when the fermentation period was extended to $48 \mathrm{~h}$, the fermentation efficiency was 20.44 and $21.44 \%$ higher for both the sorbic acid and sodium benzoate-added samples vis-a-vis control. Further, at $48 \mathrm{~h}$ of juice preservation, sorbic acid and benzoic acid recorded 25 and $27 \%$ higher fermentation efficiency, respectively, at $24 \mathrm{~h}$ of fermentation period. The $48 \mathrm{~h}$ fermentation period showed higher fermentation efficiency of 26.27 and $26.66 \%$ for sorbic acid and sodium benzoate, respectively, as compared to control. Similarly, an increasing trend of higher fermentation efficiency was observed even at fermentation period of 72 and $96 \mathrm{~h}$ for both sorbic acid and sodium benzoate as compared to the control.

Based on the results shown in Table 1, the ethanol yield remained in the range of $0.42-0.47 \mathrm{~g} \mathrm{~g}^{-1}$ in sodium benzoate-spiked samples which showed an optimal efficiency of $93 \%$, while in case of sorbic acid-spiked samples, the ethanol yield was in the range of $0.40-0.44 \mathrm{~g} \mathrm{~g}^{-1}$ which corresponds to an optimal efficiency of $92 \%$. In case of control, the ethanol yield was observed in the range of $0.36 \mathrm{~g} \mathrm{~g}^{-1}$ that reduced to $0.26 \mathrm{~g} \mathrm{~g}^{-1}$ and the optimal efficiency reduced to $57 \%$. The ethanol yields were consistent on fermentation in case of both the preservatives-spiked juice samples since the total soluble sugar content was maintained in the juice samples as compared to the control (un-spiked juice sample) which showed a reduction in the total soluble sugar content with an increase in the fermentation time. However, the sodium benzoate-spiked samples showed comparatively better results than sorbic acid-spiked samples. Since all the experiments were performed at room temperature, it is believed that the storage shelf life of sweet sorghum juice can be extended with the addition of sodium benzoate as preservative under room temperature conditions. Ethanol fermentation of greater than $90 \%$ efficiency was observed in frozen, autoclaved and juice containing $25 \%$ sugar samples, whereas less than the above was seen in normal juice fermentation (Imam and Capareda 2011). The fermentation efficiency of around $90 \%$ was also observed in fermentations performed under very high gravity conditions $(\mathrm{Nu}-$ anpeng et al. 2011). Therefore, the use of chemical preservatives employed in the present work were beneficial to enhance the storage shelf life of sweet sorghum juice with no special treatment required for the preservation of juice and the fermentation efficiency was also not compromised.

\section{Conclusions}

The results observed in the present study demonstrated that sodium benzoate and sorbic acid were suitable chemical preservatives among the tested preservatives and they preserved the fermentable sugars in the sweet sorghum stalk juice at room temperature, thus extending the storage shelf life of juice from $5 \mathrm{~h}$ (normal shelf life) to $48 \mathrm{~h}$ and also enabled the later fermentation of the juice to ethanol. On the other hand, the control juice sample with no added preservatives showed a significant reduction in the total soluble sugar content and resulted in a sharp decrease in the ethanol yield as well as the efficiency. The highest fermentation efficiency of $93 \%$ was recorded at $48 \mathrm{~h}$ incubation. The chemical preservatives identified in this study may be helpful to the biofuel and other allied industries in the development of cost-effective strategies to preserve the fermentable sugars and retain the organoleptic and rheological properties of the sweet sorghum juice during processing, transportation, and storage under normal ambient conditions as compared to refrigerated conditions which is energy-intensive.

Acknowledgments The authors gratefully acknowledge the financial support from the National Agricultural Innovation Project (NAIP)Indian Council of Agricultural Research (ICAR) under component 2 and International Fund for Agriculture Development (IFAD) through Grant no. 974.

Conflict of interest The authors have no conflict of interest with any researcher or funding agency.

\section{References}

Ariyajarearnwong, P., L. Laopaiboon, P. Jaisil, and P. Laopaiboon. 2011. Repeated-batch ethanol fermentation from sweet sorghum juice by free cells of Saccharomyces cerevisiae NP 01. African Journal of Biotechnology 10: 13909-13918.

Chum, L.M., and R.P. Overend. 2001. Biomass and renewable fuels. Fuel Bioprocessing Technology 17: 187-195.

Dubois, M., K.A. Gilles, J.K. Hamilton, P.A. Rebers, and F. Smith. 1956. Colorimetric method for determination of sugars and related substances. Analytical Chemistry 28: 350-356.

Gould, G.W. 1989. Mechanisms of action of food preservation procedures. London: Elsevier Applied Science.

Gould, G.W. 2000. Preservation: Past, present and future. British Medical Bulletin 26: 84-96.

Huilgol, R.V., Ramakrishna, and G. Misale. 2004. A trial with sweet sorghum. In Alternative Uses of Sorghum and Pearl Millet in Asia: Proceedings of the Expert Meeting, ICRISAT, Andhra Pradesh, India, 1-4 July 2003, CFC Technical paper No. 34, 333-337. Patancheru: International Crops Research Institute for the Semi-Arid Tropics.

Hussain, I., A. Zeb, and M. Ayub. 2010. Quality attributes of apple and apricot blend juice preserved with potassium sorbate during storage at low temperature. Internet Journal of Food Safety 12: $80-86$.

Hussain, I., A. Zeb, and M. Ayub. 2011. Evaluation of apple and apricot blend juice preserved with sodium benzoate at refrigeration temperature. World Journal of Agricultural Sciences 7: $136-142$.

Imam, T., and S. Capareda. 2011. Fermentation kinetics and ethanol production from different sweet sorghum varieties. International Journal of Agricultural and Biological Engineering 4: 33-40. 
Khongsay, N., L. Laopaiboon, and P. Laopaiboon. 2010. Growth and batch ethanol fermentation of Saccharomyces cerevisiae on sweet sorghum stem juice under normal and very high gravity conditions. Biotechnology 9: 9-16.

Kumar, C.G., A. Fatima, P. Srinivasa Rao, B.V.S. Reddy, A. Rathore, R. Nageswar Rao, S. Khalid, A.A. Kumar, and A. Kamal. 2010. Characterization of improved sweet sorghum genotypes for biochemical parameters, sugar yield and its attributes at different phenological stages. Sugar Tech 12: 322-328.

Kundiyana, D.K. 1996. Sorganol: In-field production of ethanol from sweet sorghum. M.Sc. Thesis. Stillwater, OK: Oklahoma State University.

Laopaiboon, L., P. Thanonkeo, P. Jaisil, and P. Laopaiboon. 2007. Ethanol production from sweet sorghum juice in batch and fedbatch fermentations by Saccharomyces cerevisiae. World Journal of Microbiology and Biotechnology 23: 1497-1501.

Laopaiboon, L., S. Nuanpeng, P. Srinophakun, P. Klanrit, and P. Laopaiboon. 2009. Ethanol production from sweet sorghum juice using very high gravity technology: Effects of carbon and nitrogen supplementations. Bioresource technology 100: 4176-4182.

Lück, F. 1990. Food applications of sorbic acid and its salts. Food Additives \& Contaminants 7: 711-715.

Manganelli, E., and A. Casolari. 1983. Sensitivity of yeasts to sorbic and benzoic acids and their salts. Ind Conserve 58: 23-25.

Miller, G.L. 1959. Use of dinitrosalicylic acid reagent for the determination of reducing sugars. Analytical Chemistry 31: 426-428.

Nuanpeng, S., L. Laopaiboon, P. Srinophakun, P. Klanrit, P. Jaisil, and P. Laopaiboon. 2011. Ethanol production from sweet sorghum juice under very high gravity conditions: Batch, repeated-batch and scale up fermentation. Electronic Journal of Biotechnology. doi: http://dx.doi.org/10.2225/vol14-issue1fulltext-2 (accessed 14 May 2014).

Reddy, B.V.S., S. Ramesh, P. Sanjana Reddy, B. Ramaiah, P.M. Salimath, and R. Kachapur. 2005. Sweet sorghum-A potential alternative raw material for bioethanol and bio-energy. International Sorghum and Millets Newsletter 46: 79-86.

Shen, H.Y., S.D. Schrijver, N. Moonjai, K.J. Verstrepen, F. Delvaux, and F.R. Delvaux. 2004. Effects of $\mathrm{CO}_{2}$ on the formation of flavor volatiles during fermentation with immobilized brewer's yeast. Applied Microbiology and Biotechnology 64: 636-643.

Sofos, J.N., and F.F. Busta. 1981. Antimicrobial activity of sorbate. Journal of Food Protection 44: 614-622.

Srinivasa Rao, P., S.S. Rao, N. Seetharama, A.V. Umakanth, P. Sanjana Reddy, B.V.S. Reddy, and C.L.L. Gowda. 2009. Sweet sorghum for biofuel and strategies for its improvement. Information bulletin No. 77. Patancheru: International Crops Research Institute for the Semi-Arid Tropics (ISBN978-92-9066-518-2).

Srinivasa Rao, P., J.V.N.S. Prasad, A.V. Umakanth, and B.V.S. Reddy. 2011. Sweet sorghum (Sorghum bicolor (L.) Moench)-A new generation water use efficient bioenergy crop. Indian Journal of Dryland Agricultural Research and Development 11: $65-79$.

Srinivasa Rao, P., C.G. Kumar, M. Jayalakshmi, A. Kamal, and B.V.S. Reddy. 2012. Feasibility of sustaining sugars in sweet sorghum stalks during post-harvest stage by exploring cultivars and chemicals: A desk study. Sugar Technology 14: 21-25.

Warth, A.D. 1985. Resistance of yeast species to benzoic and sorbic acids and to sulfur dioxide. Journal of Food Protection 48: $564-569$.

Wortmann, C.S., A.J. Liska, R.B. Ferguson, D.J. Lyon, R.N. Klein, and I. Dweikat. 2010. Dryland performance of sweet sorghum and grain crops for biofuel in Nebraska. Agronomy Journal 102: 319-326.

Wu, X., S. Staggenborg, J.L. Propheter, W.L. Rooney, J. Yu, and D. Wang. 2010. Features of sweet sorghum juice and their performance in ethanol fermentation. Industrial Crops and Products 31: 164-170.

Wyman, C.E., and B.J. Goodman. 1993. Biotechnology for production of fuels, chemicals, and materials from biomass. Applied Biochemistry and Biotechnology 39: 41-59. 